\title{
Cytokine profiling of docetaxel-resistant castration-resistant prostate cancer
}

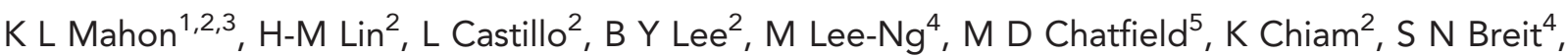 \\ D A Brown ${ }^{4}$, M P Molloy ${ }^{6}$, G M Marx ${ }^{7}$, N Pavlakis $^{8}$, M J Boyer ${ }^{1,3}$, M R Stockler ${ }^{1,3}$, R J Daly ${ }^{9}$, S M Henshall ${ }^{2}$ \\ and L G Horvath ${ }^{\star} 1,2,3$ \\ ${ }^{1}$ Chris O'Brien Lifehouse, Missenden Road, Camperdown, NSW 2050, Australia; ${ }^{2}$ Cancer Research Division, Garvan Institute of \\ Medical Research/The Kinghorn Cancer Centre, Darlinghurst, NSW 2010, Australia; ${ }^{3}$ University of Sydney, Sydney, New South \\ Wales 2050, Australia; ${ }^{4}$ St Vincent's Centre for Applied Medical Research, Liverpool Street, Darlinghurst, NSW 2010, Australia; \\ ${ }^{5}$ Menzies School of Health Research, Darwin, NT, Australia; ${ }^{6}$ Australian Proteome Analysis Facility, Macquarie University, NSW \\ 2105, Australia; ${ }^{7}$ Northern Haematology and Oncology Group, SAN Clinic, Wahroonga, NSW 2076, Australia; ${ }^{8}$ Royal North Shore \\ Hospital, Pacific Highway, Sydney, NSW 2065, Australia and ' Signalling Network Laboratory, Department of Biochemistry and \\ Molecular Biology, School of Biomedical Sciences, Monash University, Clayton, VIC 3800, Australia
}

Background: Docetaxel improves symptoms and survival in metastatic castration-resistant prostate cancer (CRPC). However, $\sim 50 \%$ of patients are chemoresistant. This study examined whether changes in cytokine levels predict for docetaxel resistance in vitro and in a clinical cohort.

Methods: PC3 cells or their docetaxel-resistant subline (PC3Rx) were co-cultured with U937 monocytes, with and without docetaxel treatment, and cytokine levels were measured. The circulating levels of 28 cytokines were measured pre-/post cycle 1 of docetaxel from 55 men with CRPC, and compared with prostate-specific antigen (PSA) response.

Results: PC3Rx-U937 co-culture expressed more cytokines, chiefly markers of alternative macrophage differentiation, compared with PC3-U937 co-culture. Docetaxel treatment enhanced cytokine production by PC3Rx-U937 co-culture, while reducing cytokine levels in PC3-U937. In patients, changes in the levels of seven circulating cytokines (macrophage inhibitory cytokine 1 (MIC1), interleukin (IL)-1 ra, IL-1 $\beta$, IL-4, IL-6, IL-12 and IFN $\gamma$ ) after cycle 1 of docetaxel were associated with progressive disease (all $P<0.05$ ). The combination of changes in MIC1, IL-4 and IL-6 most strongly predicted PSA response $(P=0.002)$.

Conclusions: In vitro studies suggest docetaxel resistance is mediated, at least in part, by cytokines induced by the interaction between the docetaxel-resistant tumour cells and macrophages. Early changes in circulating cytokine levels were associated with docetaxel resistance in CRPC patients. When considered together, these data suggest a significant role for the inflammatory response and macrophages in the development of docetaxel resistance in CRPC.

Prostate cancer is the most common cancer in men and the third leading cause of male cancer death in the developed world (Jemal et al, 2011). Although it is initially sensitive to hormonal manipulation, resistance to androgen deprivation therapy ultimately occurs. In the setting of advanced castration-resistant disease, docetaxel chemotherapy provides modest symptomatic and survival benefits at the cost of significant toxicity (Petrylak et al, 2004; Tannock et al, 2004). However, 50\% of patients will not respond to cytotoxic treatment. The decision to cease therapy is made after two to three chemotherapy cycles, as the median time to serum prostate-specific antigen (PSA) response for docetaxel is 44 days (Berthold et al, 2008). To minimise unwarranted toxicity and allow earlier progression to other potentially effective therapeutic agents such as cabazitaxel,

*Correspondence: Professor LG Horvath; E-mail: lisa.horvath@lh.org.au

Received 4 September 2014; revised 28 January 2015; accepted 30 January 2015; published online 31 March 2015

(C) 2015 Cancer Research UK. All rights reserved 0007-0920/15 
abiraterone and enzalutamide, early markers of treatment response are urgently required.

Inflammation is implicated in all stages of prostate cancer progression, from carcinogenesis (De Marzo et al, 2007) through to castration resistance and cytotoxic resistance (DomingoDomenech et al, 2006) in advanced disease. Cross-talk between tumour cells and myeloid neighbours via cytokine mediators is essential to the development of some forms of chemoresistance (Acharyya et al, 2012). In particular, tumour-associated macrophages (TAMs) are central participants in the tumour microenvironment, promoting tumour growth, angiogenesis and metastases (Mantovani et al, 2006). Baseline serum interleukin-6 (IL-6; Domingo-Domenech et al, 2007) and baseline C-reactive protein (Beer et al, 2008) have been implicated as biomarkers of chemoresistance in castration-resistant prostate cancer (CRPC). Single baseline cytokine measures are limited by the significant variability between individuals at any given time point (Wong et al, 2008). However, we postulate that measuring changes during chemotherapy would control for this interpersonal variability. We previously demonstrated that an increase in macrophage inhibitory cytokine 1 (MIC1) levels after cycle 1 of chemotherapy in men with CRPC was predictive of docetaxel resistance, as opposed to the static baseline MIC1 levels, which were not able to identify non-responders (Zhao et al, 2009). A comprehensive cytokine evaluation during therapy has not been previously performed.

The aim of this study was to investigate the role of cytokines and macrophages in docetaxel resistance in vitro and the ability of circulating cytokines to predict patient response to chemotherapy treatment and overall survival.

\section{MATERIALS AND METHODS}

Cell lines and conditioned media production. The PC3 and U937 cell lines were obtained from the American Type Culture Collection. The docetaxel-resistant cell line, PC3Rx, was developed through serial passage of PC3 with increasing docetaxel (SanofiAventis, Surrey, UK) concentrations as previously described (Zhao et al, 2009). The identity of the cell lines was authenticated by CellBank Australia (NSW, Australia). All cell lines were maintained in RPMI 1640 (Invitrogen, Carlsbad, CA, USA) with 10\% fetal bovine serum, insulin $\left(0.25 \mathrm{IU} \mathrm{ml}^{-1}\right)$, HEPES $(10 \mathrm{~mm})$ and gentamicin $\left(20 \mu \mathrm{g} \mathrm{ml}^{-1}\right)$. U937 cells were differentiated by treating with $100 \mathrm{ng} \mathrm{ml}^{-1}$ phorbol 12-myristate 13-acetate (PMA; Sigma, St Louis, MO, USA) for $24 \mathrm{~h}$ and allowed to recover for $96 \mathrm{~h}$ before docetaxel treatment. For assays requiring conditioned media from individual cell lines, cells were cultured for 3 days before culture media was replaced with fresh media with or without addition of docetaxel $\left(8 \mathrm{ng} \mathrm{ml}^{-1}\right)$. The conditioned media was collected after $24 \mathrm{~h}$, centrifuged at $1500 \mathrm{~g}$ for $5 \mathrm{~min}$ and the supernatant was stored at $-80^{\circ} \mathrm{C}$. In co-culture experiments, PC3 or PC3Rx cells were seeded together in the same flask with undifferentiated U937 cells. The media was refreshed after $24 \mathrm{~h}$ to remove non-adherent cells. Cells were treated with docetaxel $\left(8 \mathrm{ng} \mathrm{ml}^{-1}\right)$ for $24 \mathrm{~h}$ on day 3 or 7 , for 4 - or 8 -day experiments, respectively. Conditioned media was collected after $24 \mathrm{~h}$ of docetaxel exposure.

In vitro cytokine analysis. The Human Cytokine Array Panel A (R\&D Systems, Minneapolis, MN, USA) was used according to the manufacturer's instructions, to quantitate cytokines in conditioned media collected from cell culture experiments. Cytokines measured were C5/C5a, CD40L, GCSF, GMCSF, GRO $\alpha$, sICAM, I309, IFN $\gamma$, IL-1 $\alpha$, IL-1ra, IL-1 $\beta$, IL-2, IL-4, IL-5, IL-6, IL-8, IL-10, IL-12 p70, IL-13, IL-16, IL-17, IL-17E, IL-23, IL-27, IL-32 $\alpha$ MCP1, MIF, Serpin E1, RANTES, IP10, ITAC, MIP1 $\alpha$, MIP1 $\beta$, SDF1, TNF $\alpha$ and TREM1. The levels of MIC1 in conditioned media was measured with a GDF15 Quantikine kit (R\&D Systems), according to the manufacturer's instructions.

Patient samples. Blood samples for cytokine analysis were collected at baseline before chemotherapy and 3 weeks after the first dose (cycle 1) of chemotherapy just before the second cycle of treatment, from 55 men with metastatic CRPC. Castrationresistant prostate cancer was defined by PSA and/or clinical progression after maximal androgen blockade, with a minimum of 4 weeks having elapsed between the withdrawal of anti-androgens and the commencement of chemotherapy. Serum samples were obtained from 35 patients treated with docetaxel and PI-88, a heparanase inhibitor, on a phase II clinical trial, which showed that addition of PI-88 was comparable with docetaxel alone (Khasraw et al, 2010). Plasma samples were obtained from 20 patients receiving single-agent docetaxel. Plasma samples from seven healthy volunteers (two men and five women) were collected on days 1, 22 and 43. Blood samples were collected according to a standardised operating protocol, using $\mathrm{BD}$ Vacutainer tubes (BD, Plymouth, UK) containing $\mathrm{K}_{2}$ EDTA for plasma separation, or clot activator and gel for serum separation. Samples were centrifuged at $3000 \mathrm{~g}$ for $5 \mathrm{~min}$ at room temperature and stored at $-80^{\circ} \mathrm{C}$ within 30 min of collection.

Serum PSA levels were measured before each cycle of chemotherapy. Prostate-specific antigen response was defined by modified Prostate Cancer Working Group 2 criteria (Bubley et al, 1999; Scher et al, 2008); partial response (PR) was defined as a decrease from baseline by $>50 \%$ at any time during the treatment course, progressive disease (PD) was defined as an increase in PSA from baseline by $>25 \%$ in a patient without a prior defined response and stable disease (SD) was defined as change in PSA $\leqslant 50 \%$ decrease or $\leqslant 25 \%$ increase. Clinical benefit was defined as patients who achieved SD or PR. Overall survival was defined as the time from commencement of chemotherapy to the time of death. Prospective Eastern Cooperative Oncology Group performance status (ECOG PS) assessment and serum alkaline phosphatase (ALP) data were collected, but were not available in all cases. Radiological assessment was inconsistent in our cohort, prohibiting its use as a response criterion.

All patients provided written informed consent and the study was approved by relevant human research ethics review committees (Approval no. 13663).

Cytokine assay. Samples were analysed using the Bio-Plex Pro Human Cytokine 27-plex assay (Bio-Rad, Hercules, CA, USA) on a Luminex platform at the Australian Proteome Analysis Facility. Cytokines $\left(\mathrm{pg} \mathrm{ml}^{-1}\right.$ ) measured were PDGF, IL-1 $\beta$, IP10, IL-1ra, IL-2, IL-4, IL-5, IL-6, IL-7, IL-8, IL-9, IL-10, IL-12, IL-13, IL-15, IL-17, Eotaxin, $\beta$ FGF, GCSF, GMCSF, IFN $\gamma, \operatorname{MCP} 1, \operatorname{MIP} 1 \alpha$, MIP1 $\beta$, RANTES, TNF $\alpha$ and VEGF as described previously (Khan, 2012). MIC1 ( $\mathrm{pg} \mathrm{ml}^{-1}$ ) was measured using a previously described sensitive immunoassay (Selander et al, 2007).

Statistical analysis. Cytokine array signals were analysed using Image J software (Protein Array Analyser, NIH, Bethesda, MD, USA; imagej.nih.gov/ij/) and expressed as fold changes. Plasma/ serum cytokine values were transformed to logarithm scale before analysis. MIC1/IL-6/IL-4 model is the addition of changes in these cytokines over one cycle of chemotherapy. Mann-Whitney $U$-test was used to determine the relationship between cytokine levels and PSA response group. Kaplan-Meier analysis and log-rank statistic were used to measure the association between cytokine levels and survival. Cox regression analysis was used for multivariable analysis of baseline MIC1 and established prognostic factors in relation to survival. Receiver operating characteristic (ROC) curve analysis was used to measure the ability of cytokine levels, to predict response and survival. A $P$-value of $<0.05$ was required for significance and all significance tests were two sided. All statistical 
analyses were performed on SPSS software (IBM, Armonk, NY, USA). Heat map was created with GenePattern (http://www. broadinstitute.org/cancer/software/genepattern/), using the relative colour scheme.

\section{RESULTS}

Docetaxel increases cytokine production in prostate cancer cell line models. Numerous studies have analysed single cytokines in chemoresistance in vitro (Pu et al, 2004; Wilson et al, 2008; Zhao et al, 2009); however, this study aimed to assess the broad spectrum of cytokine changes associated with docetaxel resistance in vitro. Thirty-seven cytokines were measured in conditioned media from the androgen-independent prostate cancer cell line, PC3, and its docetaxel-resistant derivative, PC3Rx (Lee et al, 2014), before and after $24 \mathrm{~h}$ of docetaxel treatment. Seventeen of these cytokines were detected in any of the culture media tested (Figure 1A). The basal levels of cytokines secreted by PC3Rx differed from PC3, where PC3Rx generally had lower cytokine levels. Docetaxel treatment induced changes in cytokine secretion, which also differed between PC3 and PC3Rx. The levels of several pro-inflammatory cytokines, such as IFN $\gamma$, IL- $1 \alpha$ and RANTES were increased in docetaxeltreated PC3. In contrast, these pro-inflammatory cytokines were generally decreased in PC3Rx (Figure 1A). Interestingly, PC3Rx cells had higher basal levels of IL-10, an anti-inflammatory cytokine, which was further enhanced by docetaxel exposure (Figure 1A).

Monocyte co-culture with docetaxel-resistant prostate cancer cells increased markers of macrophage differentiation. Given that our previous study had identified $\mathrm{MIC1}$ as a potential driver of docetaxel resistance, we next considered the interaction between macrophages and prostate cancer cells using U937 cells, a promonocytic cell line, which can be induced to terminal macrophage differentiation (Sundstrom and Nilsson, 1976).

We examined the difference in cytokine production between PC3 or PC3Rx cells, with or without U937 co-culture, to assess the interaction between the macrophages and the cancer cells. When PC3 or PC3Rx were cultured together with U937 cells, U937 became adherent and differentiated into macrophages based on their appearance. Compared with PC3 or PC3Rx individual cell line cultures, conditioned media from U937 co-cultured with PC3 or PC3Rx contained reduced amounts of most cytokines (Supplementary Figure 1B and C). However, IL-1ra, a marker of U937 terminal macrophage differentiation (Roux-Lombard et al, 1989; Berger et al, 1993), and the TAM phenotype (Mantovani et al, 2004) was increased up to 3-fold in PC3/U937 co-culture and was markedly increased by up to 76-fold in PC3Rx/U937 coculture (Supplementary Figure $1 \mathrm{~B}$ and $\mathrm{C}$ ). A corresponding reduction in IL- $1 \alpha$ in co-culture, particularly after 8 days, was also seen, further evidence of macrophage differentiation (Figure 1C; Roux-Lombard et al, 1989). Cytokines, predominantly implicated in alternative differentiation and migration of macrophages, such as GMCSF, C5/C5a, IL-10, IL-27 and GRO $\alpha$, were particularly elevated in U937 co-culture with PC3Rx, compared with PC3 (Figure 1B and C). Co-culture with U937 cells reduced pro-inflammatory IFN $\gamma$ secretion by PC3 and PC3Rx (Supplementary Figure $1 \mathrm{~B}$ and $1 \mathrm{C}$ ).

Docetaxel exposure increased cytokine production in macrophage and chemo-resistant prostate cancer co-culture. The next step was to consider the effect of adding docetaxel to the co-cultures of prostate cancer cells and differentiated macrophages.
A

\begin{tabular}{|c|c|c|c|c|}
\hline A & 8 & 00 & $\mathrm{OOC}^{\circ}$ & 000 \\
\hline $\begin{array}{l}\text { Docetaxel } \\
8 \mathrm{na} \mathrm{ml}^{-1}\end{array}$ & - & & - & \\
\hline Time (days) & 4 & 4 & 4 & 4 \\
\hline Cytokine & FC & $\mathrm{FC}$ & $\mathrm{FC}$ & $\mathrm{FC}$ \\
\hline C5/C5a & 1 & 2.77 & 1.44 & 1.76 \\
\hline CD40L & 1 & 1.38 & 0.41 & 0.37 \\
\hline GCSF & 1 & 1.71 & 1.09 & \begin{tabular}{|l|}
0.63 \\
\end{tabular} \\
\hline GMCSF & 1 & 1.37 & 1.47 & 1.14 \\
\hline GRO $\alpha$ & 1 & 0.87 & 1.12 & 0.62 \\
\hline \begin{tabular}{|l|}
$1-309$ \\
\end{tabular} & 1 & 3.34 & 0.87 & \begin{tabular}{|l|}
0.23 \\
\end{tabular} \\
\hline IFN $\gamma$ & 1 & 2.38 & 0.29 & 0.58 \\
\hline IL $1 \alpha$ & 1 & 3.15 & 0.06 & 0.55 \\
\hline IL1ra & 1 & 2.94 & 0.08 & 0.39 \\
\hline IL4 & $\mathrm{NE}$ & $\mathrm{NE}$ & $\mathrm{NE}$ & $\mathrm{NE}$ \\
\hline IL6 & 1 & 1.05 & 0.08 & \begin{tabular}{|l|}
0.02 \\
\end{tabular} \\
\hline IL8 & 1 & 0.96 & 1.16 & 1.24 \\
\hline IL10 & 1 & 1.52 & 2.95 & \begin{tabular}{|l|}
7.58 \\
\end{tabular} \\
\hline IL23 & 1 & 1.20 & 0.42 & 0.41 \\
\hline IL27 & 1 & 1.75 & 2.22 & 1.03 \\
\hline MCP1 & 1 & $\mathrm{NE}$ & $\mathrm{NE}$ & $\mathrm{NE}$ \\
\hline MIF & 1 & 1.15 & 0.44 & 0.94 \\
\hline SerpinE1 & 1 & 1.00 & 0.92 & 0.96 \\
\hline RANTES & 1 & 4.14 & 8.77 & 5.70 \\
\hline MIC1 & 1 & $\mathrm{NE}$ & $\mathrm{NE}$ & $\mathrm{NE}$ \\
\hline o PC3 cells & & $2-1$ & & $0.1-0.5$ \\
\hline O PC3Rx c & & 10.0 & & $0.05-0.0$ \\
\hline o U937 cel & & a $>20$ & & a $<0.05$ \\
\hline
\end{tabular}

\begin{tabular}{|c|c|c|c|c|}
\hline B & 20 & 8 & 50 & 000 \\
\hline Docetaxel & & & & \\
\hline $8 \mathrm{ng} \mathrm{ml}^{-1}$ & - & + & - & + \\
\hline Time (days) & 4 & 4 & 4 & 4 \\
\hline Cytokine & $\mathrm{FC}$ & $\mathrm{FC}$ & $\mathrm{FC}$ & FC \\
\hline C5/C5a & 1 & $\mathrm{NE}$ & 2.12 & 3.01 \\
\hline CD40L & 1 & 0.35 & 0.09 & 0.20 \\
\hline GCSF & 1 & 0.75 & 1.45 & 3.82 \\
\hline GMCSF & 1 & 1.32 & 9.97 & 8.08 \\
\hline $\mathrm{GRO} \alpha$ & 1 & 2.32 & 6.21 & 7.89 \\
\hline I-309 & 1 & 0.18 & 1.27 & 1.36 \\
\hline $\mathrm{IFN} \gamma$ & 1 & 0.23 & 0.15 & 0.63 \\
\hline IL1 $\alpha$ & 1 & 0.29 & 0.37 & 2.25 \\
\hline IL1ra & 1 & 0.62 & 1.83 & 1.07 \\
\hline IL4 & $\mathrm{NE}$ & NE & $\mathrm{NE}$ & $\mathrm{NE}$ \\
\hline IL6 & 1 & 1.36 & 0.45 & 1.26 \\
\hline IL8 & 1 & 1.11 & 2.46 & 2.54 \\
\hline IL10 & 1 & 1.08 & 16.77 & 7.13 \\
\hline IL23 & 1 & 0.47 & 0.19 & 0.54 \\
\hline IL27 & 1 & 0.99 & 14.98 & 45.70 \\
\hline MCP1 & 1 & 0.47 & 1.69 & 1.21 \\
\hline MIF & 1 & 0.64 & 0.81 & 0.97 \\
\hline SerpinE1 & 1 & 0.93 & 0.93 & 0.99 \\
\hline RANTES & 1 & 2.46 & 44.35 & 6.92 \\
\hline MIC1 & 1 & 1.09 & NE & NE \\
\hline
\end{tabular}

NE, not expressed; sICAM, IL1 $\beta$, IL2, IL5, IL12p70, IL13, IL16, IL17, IL17E, IL32 $\alpha$, IP10, ITAC, MIP1 $\alpha$, MIP1 $\beta$, SDF1, TNF $\alpha$, STREM1.

\begin{tabular}{|c|c|c|c|c|}
\hline C & $\mathrm{O}$ & 0 & 000 & 00 \\
\hline Docetaxel & & & & \\
\hline $8 \mathrm{ng} \mathrm{ml}^{-1}$ & - & + & - & + \\
\hline Time (days) & 8 & 8 & 8 & 8 \\
\hline Cytokine & FC & $\mathrm{FC}$ & $\mathrm{FC}$ & $\mathrm{FC}$ \\
\hline C5/C5a & 1 & 0.96 & 36.21 & 7.58 \\
\hline CD40L & 1 & 1.44 & 1.79 & 1.03 \\
\hline GCSF & 1 & $\mathrm{NE}$ & 7.47 & 0.24 \\
\hline GMCSF & 1 & 0.42 & 34.30 & 15.27 \\
\hline $\mathrm{GRO} \alpha$ & 1 & 0.67 & 3.28 & 3.06 \\
\hline I-309 & 1 & $\mathrm{NE}$ & 6.91 & 3.74 \\
\hline $\mathrm{IFN} \gamma$ & 1 & 0.56 & 1.63 & 0.71 \\
\hline $\mathrm{IL} 1 \alpha$ & 1 & 0.56 & 0.41 & 0.20 \\
\hline IL1ra & 1 & 0.35 & 1.56 & 1.15 \\
\hline IL4 & $\mathrm{NE}$ & $\mathrm{NE}$ & $\mathrm{NE}$ & $\mathrm{NE}$ \\
\hline IL6 & 1 & 1.67 & 0.15 & 0.08 \\
\hline IL8 & 1 & 0.63 & 2.57 & 2.74 \\
\hline IL10 & 1 & 0.35 & 11.58 & $\mathrm{NE}$ \\
\hline IL23 & 1 & 1.16 & 1.62 & 0.99 \\
\hline IL27 & 1 & 1.12 & 12.45 & 14.73 \\
\hline MCP1 & 1 & 0.10 & 0.36 & 0.12 \\
\hline MIF & 1 & 1.22 & 1.15 & 1.05 \\
\hline SerpinE1 & 1 & 0.92 & 1.20 & 1.22 \\
\hline RANTES & 1 & 0.77 & 0.81 & 0.70 \\
\hline MIC1 & 1 & 1.55 & 4.62 & 6.00 \\
\hline
\end{tabular}

Figure 1. Comparisons of cytokine levels in conditioned media from PC3 and PC3Rx cultured alone or in co-culture with U937, with or without $24 \mathrm{~h}$ docetaxel treatment. (A) PC3 and PC3Rx with or without docetaxel (FC, fold change relative to PC3 without docetaxel). (B) PC3-U937 or PC3Rx-U937 co-culture over 4 days, with or without docetaxel treatment on Day 3 (FC, fold change relative to PC3-U937 co-culture without docetaxel). (C) PC3/U937 or PC3Rx/U937 co-culture over 8 days with or without docetaxel treatment on Day 7 (FC, fold change relative to PC3/U937 co-culture without docetaxel) 
Cytokine levels in the conditioned media of U937 cells differentiated with PMA were not significantly altered by $24 \mathrm{~h}$ docetaxel treatment of the macrophages (Supplementary Figure 1A), indicating that cytokine production by U937 was not affected by docetaxel. In contrast, the levels of numerous cytokines were increased in PC3Rx/U937 co-culture conditioned media following docetaxel exposure (C5/C5a, GCSF, GRO $\alpha$, IL- $1 \alpha$ and IL-27), whereas a generalised reduction in cytokine levels was observed in the PC3/U937 co-culture (Figure $1 \mathrm{~B}$ and C). This is in direct contrast to the individual cell line cultures described above, where docetaxel induced cytokine production in the docetaxel-sensitive PC3 cells more than in the docetaxel-resistant PC3Rx cells. Interestingly, after 4 days of co-culture, MIC1, which was not detected in conditioned media of individual cultures, was detected in PC3/U937 co-culture, but not in the PC3Rx/U937 co-culture. However, after 8 days of co-culture to improve macrophage maturity (Berger et al, 1993), MIC1 was expressed in the PC3-Rx/ U937 co-culture at higher levels than the chemosensitive counterpart. A similar pattern was seen with GMCSF (Figure 1C). These cytokines are associated with macrophage differentiation and the TAM phenotype, suggesting that the feedback mechanism in the chemoresistant co-culture promotes macrophage maturity.

Temporal variability of circulating cytokine levels. Previous clinical studies have assessed the relationship between baseline cytokine levels and response to treatment, but results are discordant (Beer et al, 2008). For that reason, we sought to assess the temporal variability of 27 cytokines in 7 healthy volunteers by assessing 3 consecutive blood samples, each taken at 3 weekly intervals. For most detectable cytokines, intersubject variability was greater than intrasubject variability (intraclass correlation coefficient $>0.5$, Supplementary Table 1 ). This reinforced the need to use paired samples rather than a single measure in time.

Patient characteristics. Plasma or serum samples were collected from a cohort of 55 men receiving docetaxel for metastatic CRPC. At a median follow-up of 15 months, median overall survival was 15 months with $84 \%$ deceased at the time of data analysis. The

Table 1. Clinicopathologic characteristics of the patient cohort $(n=55)$

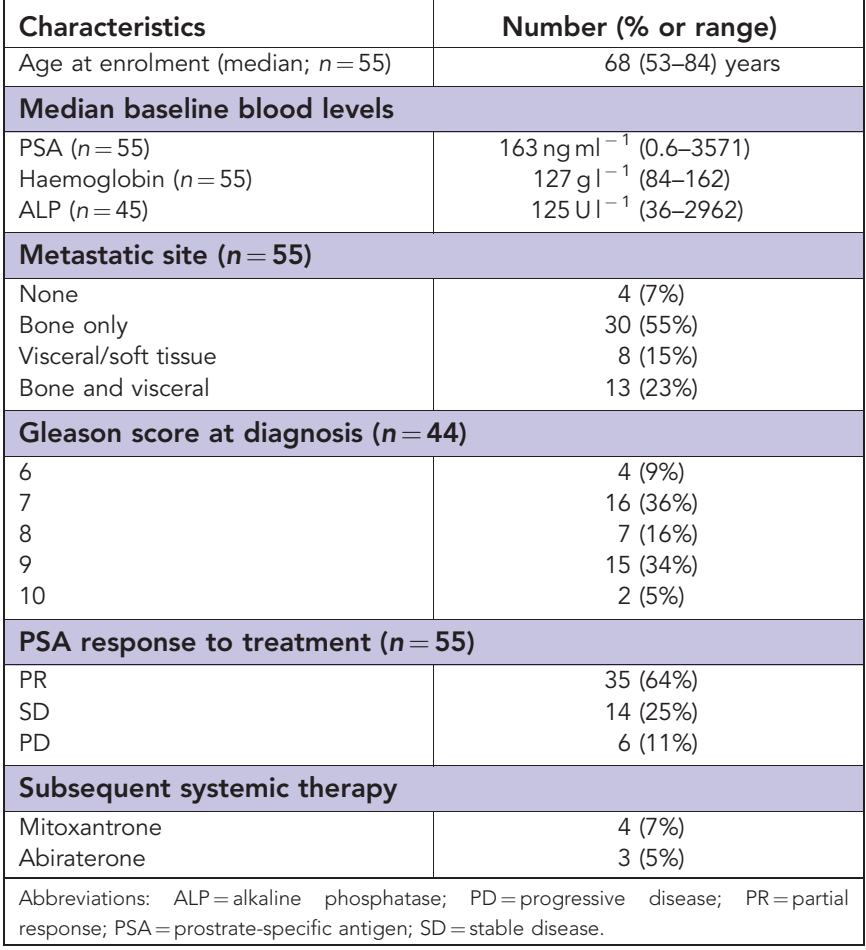

cohort clinical characteristics are summarised in Table 1. The baseline demographics of our cohort were very similar compared with the two, large phase III trials of docetaxel in CRPC, TAX327 (Tannock et al, 2004) and SWOG 99-16 (Petrylak et al, 2004). However, $64 \%$ of patients in our cohort had a fall in PSA $\geqslant 50 \%$, which was higher than the $45 \%-50 \%$ partial PSA response rates in these trials. Our cohort also had a slightly lower rate of bone and visceral/soft tissue metastases, including involvement of lymph nodes.

Changes in seven cytokines predict for chemotherapy response. The levels of 28 cytokines were quantitated in the plasma and serum samples. Six cytokines (IL-2, IL-15, IL-17, $\beta$ FGF, GMCSF and MIP $1 \alpha$ ) were below the limit of detection in $>50 \%$ of samples and were excluded from statistical analysis. The range and median of the cytokine levels in the cohort are shown in Supplementary Table 2. Seven cytokines (IL-1ra, IL-1 $\beta$, IL-4, IL-6, IL-12, IFN $\gamma$ and MIC1) had significantly increased levels after cycle 1 of chemotherapy in patients with $\mathrm{PD}$ compared with those with clinical benefit (PR or SD; Figure 2A and B). Baseline cytokine levels were not associated with chemotherapy response, as the levels were not significantly different between the clinical benefit and PD groups of patients $(P>0.05)$. Overall, both the in vitro and human data demonstrate an inflammatory response to docetaxel resistance involving pro-inflammatory mediators and cytokines involved in macrophage recruitment, activation and TAM phenotype such as IL-1ra and MIC1.

In order to identify the best model to predict docetaxel resistance, ROC curve analysis was performed. The change in IL-4 alone was the single, most accurate predictor of PD $(P=0.005$; Figure $2 \mathrm{C}$ ). Area under the curve values for each of the seven cytokines significantly associated with clinical benefit were at least 0.7 (Supplementary Table S3). The additive model of changes in IL-4, MIC1 and IL-6 had the strongest association with PD $(P=0.003$; Figure 2D). Although published data from our group and others have identified a direct role for IL-6 and MIC1 in chemoresistance in CRPC (Borsellino et al, 1995; Pu et al, 2004; Huang et al, 2007; Zhao et al, 2009), the addition of recombinant human IL-4 (rhIL-4) to androgen-independent prostate cancer cells does not alter docetaxel cytotoxicity (Supplementary Figure 2).

Pre-treatment MIC1 level predicts for overall survival. Circulating MIC1 levels have prognostic utility in all stages of prostate cancer (Brown et al, 2009). In our cohort, patients with baseline MIC1 levels greater than the median (5591 $\left.\mathrm{pg} \mathrm{ml}^{-1}\right)$ had a significantly shorter overall survival $(P<0.001$, Figure $3 \mathrm{~A})$. Although previous studies have established a normal MIC1 level to be below 1070-1150 $\mathrm{pg} \mathrm{ml}^{-1}$ (Koopmann et al, 2004; Selander et al, 2007), too few patients in our cohort of metastatic CRPC had normal values to use this as a discriminator. For illustrative purposes, we chose to use the median value as a cut-point for Kaplan-Meier analysis. This showed that baseline MIC1 was a superior prognostic marker to $a \geqslant 30 \%$ fall in PSA within 3 months (Figure $3 \mathrm{~A}$ and $\mathrm{B}$ ). As a continuous variable on ROC curve analysis, baseline $\mathrm{MIC1}$ was a better predictor of death within 12 months than maximal change in PSA over 3 months (Figure 3C).

In multivariable Cox proportional hazards analysis with available established prognostic factors (Halabi et al, 2003; presence of visceral metastases, Gleason score, baseline ALP, baseline $\mathrm{Hb}$, baseline PSA and PSA response to chemotherapy), baseline $\mathrm{MIC1}$ was an independent predictor of overall survival (HR: 2.73 , 95\% CI: $1.18-6.32 ; P=0.02$; Table 2 ). The ECOG PS and $\mathrm{LDH}$ level were excluded from analysis due to insufficient available data. LDH is not routinely measured as part of Australian practice. Baseline measures of the remaining cytokines were not associated with survival $(P>0.05)$. The additive model of changes 
A

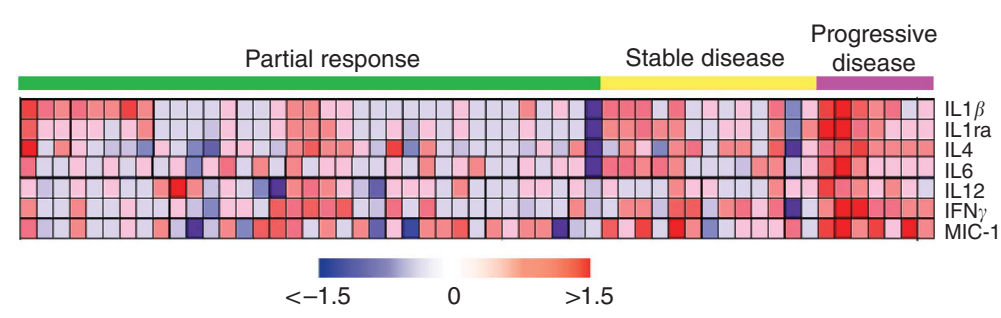

Change in cytokine levels after one cycle of chemotherapy (log normalised)
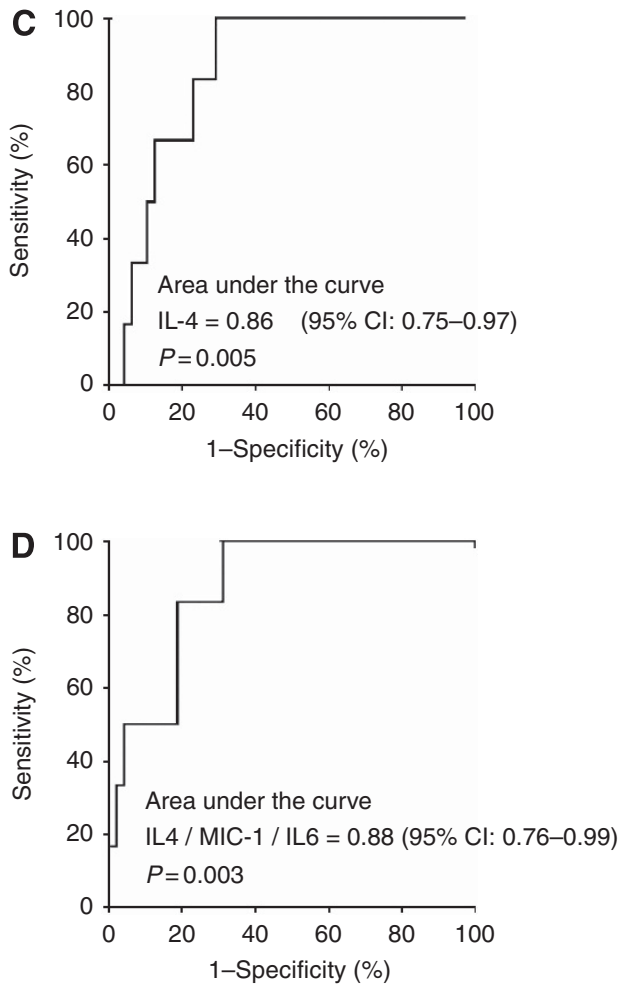

Figure 2. The relationship between changes in cytokine levels after cycle 1 of chemotherapy and chemotherapy response. (A) Heat map of changes in seven cytokine levels after cycle 1 that are significantly different between clinical benefit (PR or SD) and PD groups. (B) P-values from Mann-Whitney U-test comparing cytokine fold changes (FC) between clinical benefit and PD groups. (C) ROC analysis assessing the efficacy of a change in IL4 after cycle 1 to predict PD. (D) ROC analysis assessing the efficacy of combined changes in IL4, MIC1 and IL6 levels after cycle 1 to predict PD.

in IL-4, MIC1 and IL-6 was also not associated with overall survival (Table 2).

\section{DISCUSSION}

This study demonstrates that chemotherapy resistance both in vitro and in patients is associated with an inflammatory response involving cytokines linked to macrophage recruitment and activation. In vitro, co-culture of docetaxel-resistant prostate cancer cells with macrophages results in upregulation of secreted inflammatory cytokines compared with docetaxel-sensitive prostate cancer cells. The addition of docetaxel to the co-culture enhances cytokine production. Furthermore, human correlative studies identified a circulating cytokine profile that is associated with treatment response in CRPC patients.

This is the first study to comprehensively evaluate temporal changes in circulating cytokines rather than single measures, which have had limited utility thus far (Beer et al, 2008). The clinical and in vitro findings suggest a role for pro-inflammatory cytokines and macrophages in the development of docetaxel resistance in CRPC. Patients who respond poorly to chemotherapy (PD) have increased levels of IL-1ra, a marker of macrophage differentiation (Janson et al, 1991), which was also produced at higher levels by monocyte co-cultures with docetaxel-resistant prostate cancer cells compared with docetaxel-sensitive cells. Similarly, MIC1, also associated with macrophage function ( $\mathrm{Wu}$ et al, 2010), was increased in patients with $\mathrm{PD}$ and in monocyte co-culture with docetaxel-resistant prostate cancer cells compared with docetaxel-sensitive cells.

The cytokine profiles of the in vitro cell models and patients are not in exact concordance, which is not surprising as the in vitro models do not reflect the contributions by other immune cells and tissues. For example, IL-4, another cytokine that was significantly elevated in non-responders after one cycle of chemotherapy was not produced by any of the cell lines, indicating that it is likely to be produced by non-tumour cells, such as $\mathrm{T}$ cells. In vitro, the addition of rhIL-4 to PC-3 cells did not alter their docetaxel sensitivity, suggesting that IL-4 does not have a direct effect on cancer cells to produce chemoresistance. Nevertheless, IL-4 may be involved in the chemoresistance role of macrophages, as it promotes the proliferation of resident macrophages (Jenkins et al, 2013).

A central role of IL-4, together with IL-13, is to promote the alternative activation of macrophages (Gordon, 2003) creating a distinct macrophage cellular profile that has been linked to tumour progression. Macrophages can be activated through two main pathways: (1) the classical pathway via response to microbial products or IFN $\gamma$-producing M1 macrophages, which are phagocytic and pro-inflammatory, and (2) the alternative pathway via various signals including IL-4- and IL-13-producing M2 macrophages (Gordon, 2003). Tumour-associated macrophages have similar properties to M2 macrophages and are well-described participants in the tumour microenvironment (Mantovani et al, 2006). In co-culture with a variety of tumour cells (Hagemann et al, 2006; Weigert et al, 2007; Honda et al, 2011; MullerQuernheim et al, 2012), monocytes adopt this cellular phenotype. High levels of intra-tumoral macrophages in resected localised prostate cancer correlate with increased risk of biochemical recurrence (Gannon et al, 2009). In vivo, co-inoculation of PC3 xenograft mice with macrophages alternatively activated with IL-4 promoted tumour growth (Craig et al, 2008). In other tumours such as breast cancer and myeloma, co-culture with macrophages induces chemoresistance to multiple agents (Zheng et al, 2009; Shree et al, 2011). Circulating IL-4 has not previously been implicated as a clinical marker of chemoresistance. However, our 

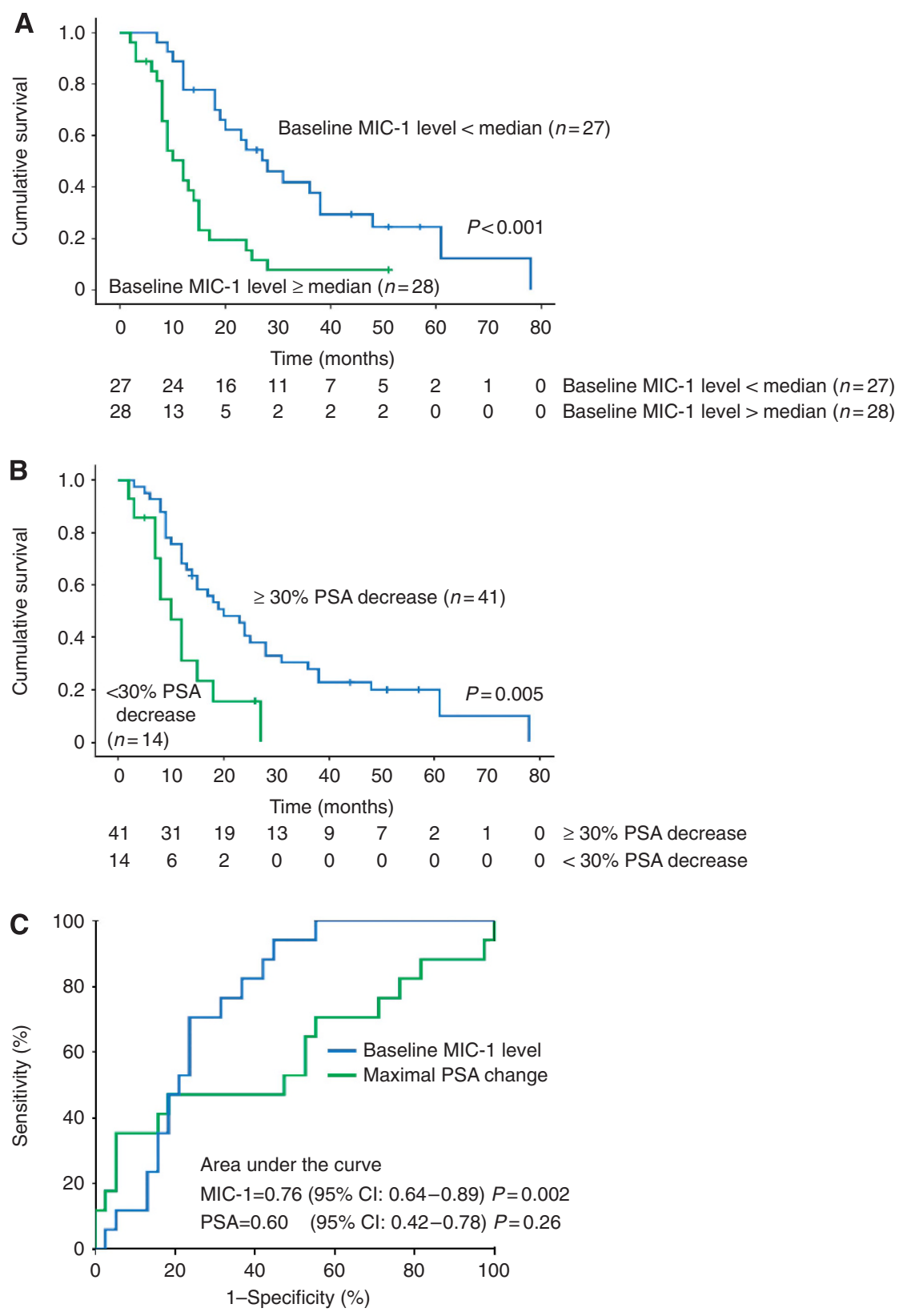

Figure 3. Baseline MIC1 levels and change in PSA after chemotherapy as predictors of overall survival. (A) Kaplan-Meier analysis demonstrating that a baseline MIC1 level greater than the median confers a poorer overall survival. (B) Kaplan-Meier analysis of the relationship between a $\geqslant 30 \%$ decline in PSA at 3 months after commencing chemotherapy and overall survival. (C) ROC curve revealing baseline MIC1 level is superior to maximal change in PSA within 3 months in predicting death within 12 months of commencing chemotherapy.

results suggest links to a key role for macrophages in docetaxel resistance in CRPC.

IL-6, also highly correlated with response to treatment in our cohort, has long been directly implicated in chemoresistance, in both preclinical and clinical studies. Inhibition of IL-6 enhances chemosensitivity in vitro, whereas exogenous IL-6 inhibits cytotoxic drug-induced apoptosis (Borsellino et al, 1995; Pu et al, 2004) potentially via the $\mathrm{Bcl}$ and Stat signalling pathways ( $\mathrm{Pu}$ et al, 2004). In relation to macrophage activity, IL-6 reciprocally upregulates the expression of MCP1, a chemotactic factor responsible for the recruitment of monocytes and found in high levels in metastatic prostate tumour tissue (Roca et al, 2009). In CRPC patients receiving docetaxel chemotherapy, elevated baseline serum IL-6 levels inversely correlate with response, time to progression and prostate cancer-specific and overall survival (Domingo-Domenech et al, 2007; Visa et al, 2009). A chimeric
anti-IL-6 antibody (CNTO 328) has been shown to inhibit prostate cancer xenograft growth (Smith and Keller, 2001; Wallner et al, 2006). However, a randomised phase II study of CNTO 328 or placebo in combination with mitoxantrone was terminated early due to more deaths in the experimental arm (Fizazi et al, 2012). Further development of anti-IL-6 therapy in CRPC has failed to progress.

The correlation of MIC1 with docetaxel resistance in our cohort was not unexpected, as it has been previously implicated in vitro and clinically. Androgen-independent cell lines, PC3 and DU145, overexpress $\mathrm{MIC1}$ after docetaxel or mitoxantrone exposure (Huang et al, 2007). Our group has previously shown that treatment with exogenous MIC1 increases cellular resistance to docetaxel, whereas siRNA knockdown of MIC1 in docetaxelresistant PC3Rx cells restores chemosensitivity (Zhao et al, 2009). In our previous study with a smaller clinical cohort, an increase in 
Table 2. Cox proportional hazards model of factors that predict overall survival in men with CRPC receiving docetaxel ( $n=55$ )

\begin{tabular}{|c|c|c|c|c|c|}
\hline \multirow[b]{2}{*}{ Variable } & \multirow[b]{2}{*}{$n$} & \multicolumn{2}{|c|}{ Univariable } & \multicolumn{2}{|c|}{ Multivariable } \\
\hline & & HR $(95 \% \mathrm{Cl})$ & $P$-value & $\mathrm{HR}(95 \% \mathrm{Cl})$ & $P$-value \\
\hline Baseline MIC-1 level > median vs $\leqslant$ median & 55 & $2.819(1.517-5.240)$ & 0.001 & $2.728(1.178-6.32)$ & 0.02 \\
\hline Hemoglobin ${ }^{a}, g^{-1}$ & 55 & $0.013(0.001-0.141)$ & $<0.001$ & $0.025(0.02-0.308)$ & 0.004 \\
\hline Serum alkaline phosphatase ${ }^{a}, I U I^{-1}$ & 45 & $1.688(1.246-2.286)$ & 0.001 & $1.34(0.928-1.936)$ & 0.1 \\
\hline Progressive disease on chemotherapy (PD vs SD + PR) & 55 & $3.462(1.327-9.037)$ & 0.011 & $2.288(0.51-10.36)$ & 0.3 \\
\hline Baseline serum PSA ${ }^{a}, \mathrm{ng} \mathrm{ml}^{-1}$ & 55 & $1.356(1.093-1.681)$ & 0.006 & $1.095(0.786-1.525)$ & 0.6 \\
\hline Fall in PSA over 12 weeks $<30 \%$ vs $\geqslant 30 \%$ & 55 & $2.591(1.288-5.209)$ & 0.008 & $1.271(0.465-3.474)$ & 0.6 \\
\hline Gleason score & 44 & $1.222(0.887-1.683)$ & 0.2 & - & - \\
\hline Metastatic site & 55 & & & & \\
\hline None & & $0.47(0.14-2.50)$ & 0.5 & & \\
\hline Bone only & & 1.0 & & & \\
\hline Visceral/soft tissue & & $2.64(1.15-6.10)$ & 0.02 & - & - \\
\hline Bone and visceral & & $2.82(1.36-5.83)$ & 0.05 & & \\
\hline $\begin{array}{l}\text { Change in MIC1/IL-4/IL-6 levels after cycle } 1 \\
\text { chemotherapy }\end{array}$ & 55 & $1.019(0.882-1.177)$ & 0.8 & - & - \\
\hline
\end{tabular}

MIC1 after the first chemotherapy cycle was correlated with chemoresponse and overall survival (Zhao et al, 2009). In our current cohort, docetaxel response data were similar; however, the baseline MIC1 was more closely associated with overall survival. These differences are most probably related to the larger patient numbers in the present cohort and the greater homogeneity of therapy. In other cancers, such as glioblastoma multiforme, MIC1 has been implicated in the promotion of tumour-associated M2-type macrophages (Wu et al, 2010). The significance of circulating MIC1 in our cohort further highlights the link with macrophage activity.

TAMs and immune responses, in particular the TH2 responses, have been extensively associated with the initiation and progression of cancer. TH2 T cells are stimulated by TAMs and myeloidderived suppressor cells, resulting in the skewing of adaptive tumour-specific immunity and the development of a tumour microenvironment that predisposes to tumour proliferation (Disis, 2010). The cytokine profiles in the in vitro and human data, both identified cytokines involved in TAM activation and inflammation upregulation in docetaxel resistance. Interestingly, a six-gene prognostic model for CRPC based on whole-blood RNA transcript profiling has recently been developed, in which all genes are modulators of the immune system (Ross et al, 2012). Furthermore, three of these genes, which are upregulated in poor prognosis disease (C1QA, TIMP1 and CDKN1A) drive monocyte differentiation towards the production of tissue macrophages, while the other three downregulated genes (ABL2, ITGAL and SEMA4D) are components of an integrated system required for T-cell motility, antigen surveillance and T-helper cell activity (Ross et al, 2012). These immune aberrations are now being targeted successfully by CTLA-4 and PD-1 inhibitors in melanoma (Topalian et al, 2012) and therefore may be useful in overcoming docetaxel resistance in CRPC.

Of the dominant cytokines identified in the clinical cohort, in vitro evidence suggests that IL-6 and MIC1 directly alter the response of prostate cancer cells to docetaxel and increase macrophage recruitment and alternative differentiation. The involvement of IL-4 is more complex. Although it does not directly influence prostate cancer cell chemoresistance, it may drive docetaxel resistance as a key mediator of resident macrophage differentiation to TAMs.

In conclusion, we have identified cytokines associated with docetaxel resistance in CRPC patients. The in vitro and human correlative data suggest a relationship between macrophage- associated cytokines and docetaxel resistance in CRPC. These results provide the basis for validation of the IL-4/MIC1/IL-6 model as an early therapeutic-response biomarker and propose strategies to overcome docetaxel resistance.

\section{ACKNOWLEDGEMENTS}

We thank the Cancer Institute New South Wales, National Health and Medical Research Council, Australian Cancer Research Foundation, Cancer Australia, Prostate Cancer Foundation of Australia, RT Hall Trust, Tour de Cure, and Sydney Catalyst and Cancer Council NSW. We thank the late Robert L Sutherland for his role in the development and support of this project.

\section{REFERENCES}

Acharyya S, Oskarsson T, Vanharanta S, Malladi S, Kim J, Morris PG, Manova-Todorova K, Leversha M, Hogg N, Seshan VE, Norton L, Brogi E, Massague J (2012) A CXCL1 paracrine network links cancer chemoresistance and metastasis. Cell 150(1): 165-178.

Beer TM, Lalani AS, Lee S, Mori M, Eilers KM, Curd JG, Henner WD, Ryan CW, Venner P, Ruether JD, Chi KN (2008) C-reactive protein as a prognostic marker for men with androgen-independent prostate cancer: results from the ASCENT trial. Cancer 112(11): 2377-2383.

Berger AE, Carter DB, Hankey SO, McEwan RN (1993) Cytokine regulation of the interleukin-1 receptor antagonist protein in U937 cells. Eur J Immunol 23(1): 39-45.

Berthold DR, Pond GR, Roessner M, de Wit R, Eisenberger M, Tannock IF (2008) Treatment of hormone-refractory prostate cancer with Docetaxel or Mitoxantrone: relationships between prostate-specific antigen, pain, and quality of life response and survival in the TAX-327 study. Clin Cancer Res 14: 2763-2767.

Borsellino N, Belldegrun A, Bonavida B (1995) Endogenous interleukin 6 is a resistance factor for cis-diamminedichloroplatinum and etoposidemediated cytotoxicity of human prostate carcinoma cell lines. Cancer Res 55(20): 4633-4639.

Brown DA, Lindmark F, Stattin P, Balter K, Adami HO, Zheng SL, Xu J, Isaacs WB, Gronberg H, Breit SN, Wiklund FE (2009) Macrophage inhibitory cytokine 1: a new prognostic marker in prostate cancer. Clin Cancer Res 15(21): 6658-6664.

Bubley GJ, Carducci M, Dahut W, Dawson N, Daliani D, Eisenberger M, Figg WD, Freidlin B, Halabi S, Hudes G, Hussain M, Kaplan R, Myers C, 
Oh W, Petrylak DP, Reed E, Roth B, Sartor O, Scher H, Simons J, Sinibaldi V, Small EJ, Smith MR, Trump DL, Wilding G et al. (1999) Eligibility and response guidelines for phase II clinical trials in androgenindependent prostate cancer: recommendations from the Prostate-Specific Antigen Working Group. J Clin Oncol 17(11): 3461-3467.

Craig M, Ying C, Loberg RD (2008) Co-inoculation of prostate cancer cells with U937 enhances tumor growth and angiogenesis in vivo. J Cell Biochem 103(1): 1-8.

De Marzo AM, Platz EA, Sutcliffe S, Xu J, Gronberg H, Drake CG, Nakai Y, Isaacs WB, Nelson WG (2007) Inflammation in prostate carcinogenesis. Nat Rev Cancer 7(4): 256-269.

Disis ML (2010) Immune regulation of cancer. J Clin Oncol 28: 4631-4638.

Domingo-Domenech J, Martinez-Fernandez A, Garcia-Albeniz X,

Fernandez P, Filella X, Gascon P, Mellado B (2007) Correlation of serum interleukin-6 (IL-6) levels with immunohistochemical p65/nuclear factor$\{$ kappa $\}$ B (NF-\{kappa\}B) expression and prediction of the clinical outcome of hormone-independent prostate cancer patients (HIPC) treated with docetaxel (D). ASCO Meeting Abstracts 25(18_suppl): 5075.

Domingo-Domenech J, Oliva C, Rovira A, Codony-Servat J, Bosch M, Filella X, Montagut C, Tapia M, Campas C, Dang L, Rolfe M, Ross JS, Gascon P, Albanell J, Mellado B (2006) Interleukin 6, a nuclear factorkappaB target, predicts resistance to docetaxel in hormone-independent prostate cancer and nuclear factor-kappaB inhibition by PS-1145 enhances docetaxel antitumor activity. Clin Cancer Res 12(18): 5578-5586.

Fizazi K, De Bono JS, Flechon A, Heidenreich A, Voog E, Davis NB, Qi M, Bandekar R, Vermeulen JT, Cornfeld M, Hudes GR (2012) Randomised phase II study of siltuximab (CNTO 328), an anti-IL-6 monoclonal antibody, in combination with mitoxantrone/prednisone versus mitoxantrone/prednisone alone in metastatic castration-resistant prostate cancer. Eur J Cancer 48(1): 85-93.

Gannon PO, Poisson AO, Delvoye N, Lapointe R, Mes-Masson AM, Saad F (2009) Characterization of the intra-prostatic immune cell infiltration in androgen-deprived prostate cancer patients. J Immunol Methods 348(1-2): 9-17.

Gordon S (2003) Alternative activation of macrophages. Nat Rev Immunol 3(1): $23-35$.

Hagemann T, Wilson J, Burke F, Kulbe H, Li NF, Pluddemann A, Charles K, Gordon S, Balkwill FR (2006) Ovarian cancer cells polarize macrophages toward a tumor-associated phenotype. J Immunol 176(8): 5023-5032.

Halabi S, Small EJ, Kantoff PW, Kattan MW, Kaplan EB, Dawson NA, Levine EG, Blumenstein BA, Vogelzang NJ (2003) Prognostic model for predicting survival in men with hormone-refractory metastatic prostate cancer. J Clin Oncol 21(7): 1232-1237.

Honda T, Inagawa H, Yamamoto I (2011) Differential expression of mRNA in human monocytes following interaction with human colon cancer cells. Anticancer Res 31(7): 2493-2497.

Huang CY, Beer TM, Higano CS, True LD, Vessella R, Lange PH, Garzotto M, Nelson PS (2007) Molecular alterations in prostate carcinomas that associate with in vivo exposure to chemotherapy: identification of a cytoprotective mechanism involving growth differentiation factor 15 . Clin Cancer Res 13(19): 5825-5833.

Janson RW, Hance KR, Arend WP (1991) Production of IL-1 receptor antagonist by human in vitro-derived macrophages. Effects of lipopolysaccharide and granulocyte-macrophage colony-stimulating factor. J Immunol 147(12): 4218-4223.

Jemal A, Bray F, Center MM, Ferlay J, Ward E, Forman D (2011) Global cancer statistics. CA Cancer J Clin 61(2): 69-90.

Jenkins SJ, Ruckerl D, Thomas GD, Hewitson JP, Duncan S, Brombacher F, Maizels RM, Hume DA, Allen JE (2013) IL-4 directly signals tissueresident macrophages to proliferate beyond homeostatic levels controlled by CSF-1. J Exp Med 210(11): 2477-2491.

Khan A (2012) Detection and quantitation of forty eight cytokines, chemokines, growth factors and nine acute phase proteins in healthy human plasma, saliva and urine. J Proteomics 75(15): 4802-4819.

Khasraw M, Pavlakis N, McCowatt S, Underhill C, Begbie S, de Souza P, Boyce A, Parnis F, Lim V, Harvie R, Marx G (2010) Multicentre phase I/II study of PI-88, a heparanase inhibitor in combination with docetaxel in patients with metastatic castrate-resistant prostate cancer. Ann Oncol 21(6): 1302-1307.

Koopmann J, Buckhaults P, Brown DA, Zahurak ML, Sato N, Fukushima N, Sokoll LJ, Chan DW, Yeo CJ, Hruban RH, Breit SN, Kinzler KW, Vogelstein B, Goggins M (2004) Serum macrophage inhibitory cytokine 1 as a marker of pancreatic and other periampullary cancers. Clin Cancer Res 10(7): 2386-2392.

Lee BY, Hochgrafe F, Lin HM, Castillo L, Wu J, Raftery MJ, Martin Shreeve S, Horvath LG, Daly RJ (2014) Phosphoproteomic profiling identifies focal adhesion kinase as a mediator of docetaxel resistance in castrate-resistant prostate cancer. Mol Cancer Ther 13(1): 190-201.

Mantovani A, Schioppa T, Porta C, Allavena P, Sica A (2006) Role of tumor-associated macrophages in tumor progression and invasion. Cancer Metastasis Rev 25(3): 315-322.

Mantovani A, Sica A, Sozzani S, Allavena P, Vecchi A, Locati M (2004) The chemokine system in diverse forms of macrophage activation and polarization. Trends Immunol 25(12): 677-686.

Muller-Quernheim UC, Potthast L, Muller-Quernheim J, Zissel G (2012) Tumor-cell co-culture induced alternative activation of macrophages is modulated by interferons in vitro. J Interferon Cytokine Res 32(4): 169-177.

Petrylak DP, Tangen CM, Hussain MH, Lara Jr. PN, Jones JA, Taplin ME, Burch PA, Berry D, Moinpour C, Kohli M, Benson MC, Small EJ, Raghavan D, Crawford ED (2004) Docetaxel and estramustine compared with mitoxantrone and prednisone for advanced refractory prostate cancer. N Engl J Med 351(15): 1513-1520.

Pu YS, Hour TC, Chuang SE, Cheng AL, Lai MK, Kuo ML (2004) Interleukin-6 is responsible for drug resistance and anti-apoptotic effects in prostatic cancer cells. Prostate 60(2): 120-129.

Roca H, Varsos ZS, Sud S, Craig MJ, Ying C, Pienta KJ (2009) CCL2 and interleukin-6 promote survival of human $\mathrm{CD} 11 \mathrm{~b}+$ peripheral blood mononuclear cells and induce M2-type macrophage polarization. J Biol Chem 284(49): 34342-34354.

Ross RW, Galsky MD, Scher HI, Magidson J, Wassmann K, Lee GS, Katz L, Subudhi SK, Anand A, Fleisher M, Kantoff PW, Oh WK (2012) A whole-blood RNA transcript-based prognostic model in men with castration-resistant prostate cancer: a prospective study. Lancet Oncol 13(11): 1105-1113.

Roux-Lombard P, Modoux C, Dayer JM (1989) Production of interleukin-1 (IL1) and a specific IL-1 inhibitor during human monocyte-macrophage differentiation: influence of GM-CSF. Cytokine 1(1): 45-51.

Scher HI, Halabi S, Tannock I, Morris M, Sternberg CN, Carducci MA, Eisenberger MA, Higano C, Bubley GJ, Dreicer R, Petrylak D, Kantoff P, Basch E, Kelly WK, Figg WD, Small EJ, Beer TM, Wilding G, Martin A, Hussain M (2008) Design and end points of clinical trials for patients with progressive prostate cancer and castrate levels of testosterone: recommendations of the Prostate Cancer Clinical Trials Working Group. J Clin Oncol 26(7): 1148-1159.

Selander KS, Brown DA, Sequeiros GB, Hunter M, Desmond R, Parpala T, Risteli J, Breit SN, Jukkola-Vuorinen A (2007) Serum macrophage inhibitory cytokine- 1 concentrations correlate with the presence of prostate cancer bone metastases. Cancer Epidemiol Biomarkers Prev 16(3): 532-537.

Shree T, Olson OC, Elie BT, Kester JC, Garfall AL, Simpson K, Bell-McGuinn KM, Zabor EC, Brogi E, Joyce JA (2011) Macrophages and cathepsin proteases blunt chemotherapeutic response in breast cancer. Genes Dev 25(23): 2465-2479.

Smith PC, Keller ET (2001) Anti-interleukin-6 monoclonal antibody induces regression of human prostate cancer xenografts in nude mice. Prostate 48(1): 47-53.

Sundstrom C, Nilsson K (1976) Establishment and characterization of a human histiocytic lymphoma cell line (U-937). Int J Cancer 17(5): 565-577.

Tannock IF, de Wit R, Berry WR, Horti J, Pluzanska A, Chi KN, Oudard S, Theodore C, James ND, Turesson I, Rosenthal MA, Eisenberger MA (2004) Docetaxel plus prednisone or mitoxantrone plus prednisone for advanced prostate cancer. N Engl J Med 351(15): 1502-1512.

Topalian SL, Hodi FS, Brahmer JR, Gettinger SN, Smith DC, McDermott DF, Powderly JD, Carvajal RD, Sosman JA, Atkins MB, PD Leming, Spigel DR, Antonia SJ, Horn L, Drake CG, Pardoll DM, Chen L, Sharfman WH, Anders RA, Taube JM, McMiller TL, Xu H, Korman AJ, Jure-Kunkel M, Agrawal S, McDonald D, Kollia GD, Gupta A, Wigginton JM, Sznol M (2012) Safety, activity, and immune correlates of anti-PD-1 antibody in cancer. N Engl J Med 366(26): 2443-2454.

Visa L, Pineda E, Farrus B, Codony-Servat J, Filella X, Albiol S, Martinez A, Domingo-Domench JM, Gascon P, Mellado B (2009) Correlation of serum interleukin-6 (IL-6) levels and clinical outcome in hormone-independent (HI) prostate cancer (PC) patients (PTS) treated with docetaxel. ASCO Meeting Abstracts. J Clin Oncol 27(15S): e16044. 
Wallner L, Dai J, Escara-Wilke J, Zhang J, Yao Z, Lu Y, Trikha M, Nemeth JA, Zaki MH, Keller ET (2006) Inhibition of interleukin-6 with CNTO328, an anti-interleukin-6 monoclonal antibody, inhibits conversion of androgendependent prostate cancer to an androgen-independent phenotype in orchiectomized mice. Cancer Res 66(6): 3087-3095.

Weigert A, Tzieply N, von Knethen A, Johann AM, Schmidt H, Geisslinger G, Brune B (2007) Tumor cell apoptosis polarizes macrophages role of sphingosine-1-phosphate. Mol Biol Cell 18(10): 3810-3819.

Wilson C, Purcell C, Seaton A, Oladipo O, Maxwell PJ, O'Sullivan JM, Wilson RH, Johnston PG, Waugh DJJ (2008) Chemotherapy-induced CXC-chemokine/CXC-chemokine receptor signaling in metastatic prostate cancer cells confers resistance to oxaliplatin through potentiation of nuclear factor-kappaB transcription and evasion of apoptosis. J Pharmacol Exp Ther 327(3): 746-759.

Wong HL, Pfeiffer RM, Fears TR, Vermeulen R, Ji S, Rabkin CS (2008) Reproducibility and correlations of multiplex cytokine levels in asymptomatic persons. Cancer Epidemiol Biomarkers Prev 17(12): 3450-3456.
Wu A, Wei J, Kong LY, Wang Y, Priebe W, Qiao W, Sawaya R, Heimberger AB (2010) Glioma cancer stem cells induce immunosuppressive macrophages/ microglia. Neuro Oncol 12(11): 1113-1125.

Zhao L, Lee BY, Brown DA, Molloy MP, Marx GM, Pavlakis N, Boyer MJ, Stockler MR, Kaplan W, Breit SN, Sutherland RL, Henshall SM, Horvath LG (2009) Identification of candidate biomarkers of therapeutic response to docetaxel by proteomic profiling. Cancer Res 69(19): 7696-7703.

Zheng Y, Cai Z, Wang S, Zhang X, Qian J, Hong S, Li H, Wang M, Yang J, Yi Q (2009) Macrophages are an abundant component of myeloma microenvironment and protect myeloma cells from chemotherapy druginduced apoptosis. Blood 114(17): 3625-3628.

This work is published under the standard license to publish agreement. After 12 months the work will become freely available and the license terms will switch to a Creative Commons AttributionNonCommercial-Share Alike 4.0 Unported License.

Supplementary Information accompanies this paper on British Journal of Cancer website (http://www.nature.com/bjc) 